\title{
REFERENCES
}

\section{Sources of Additional Information}

Control of Communicable Diseases in Man. American

Public Health Association, 15th Edition, New York, 1990.

Diagnosis and Treatment of Diseases of Tactical Importance to US CENTCOM Forces, 1991. Office of the US Army Surgeon General, Falls Church, VA 22041 (2nd Edition fanuary 1991).

Geissler, E. Biological and Toxin Weapons Today. Stockholm International Peace Research Institute, Oxford University Press, New York, 1986.

Health Aspects of Chemical and Biological Weapons. Report of WHO Group Consultants, WHO, Geneva, 1970.

Mandell, G., Douglas, R., Bennett, F. Principles and Practice of Infectious Diseases, 3rd Edition. Churchill Livingstone, New York, 1990.

Manual of NBC Defence Training on Land. (AC NO 71328/ap 3395, 2nd Edition/BR 8456.) Pamphlet No 6. A NBC Guide for Medical Personnel.

NATO Handbook on Medical Aspects of NBC Defensive Operations. Part 3 (Chemical) (AmedP-6(B)).

NATO Handbook on the Concept of Medical Support in NBC Environments. (AmedP-7(a)).

Wiener, S. and Barret, F. Trauma Management for Civilian and Military Physicians. W. B. Saunders and Co., Philadelphia, PA, 1986. 